\title{
Damage Analysis for Hypervelocity Impact Experiments on Spaceship Windows Glass
}

\author{
Jiyun Yang ${ }^{1, a}$, Jidong Zhang ${ }^{1}$, Zizheng, Gong ${ }^{1}$, and Hewei Pang ${ }^{2}$ \\ ${ }^{1}$ Beijing Institute of Spacecraft Environment Engineering, P.O.Box 5142-100, Beijing, 100094, P. R. \\ China \\ ${ }^{2}$ China Academy of Space Technology, P.O.Box 5142, Beijing, 100094, P. R. China
}

\begin{abstract}
The hypervelocity impact characteristics in fused silica glass, which is used for the outermost pane of the windshield as the critical part of the thermal protection system of spacecraft, were studied by 37 impact experiments with different millimeter diameter projectiles up to the velocity of $7 \mathrm{~km} / \mathrm{s}$ launched by two stage light-gas-gun facility. The empirical damage equations were obtained from experiment data by the least square method and they were compared with NASA damage equations.
\end{abstract}

\section{Introduction}

As one of the important parts of the spaceship, windows are at the risk of impact from micrometeoroid and orbital debris in the space. Fused silica glass, which is used for the outermost pane of the window as the critical part of the thermal protection system of spaceship, has low coefficient of thermal expansion and exceptional optical quality. Some experiments had been conducted to obtain hypervelocity impact characteristics of fused silica glass [1-5]. The ratio of diameter to depth of the impact crater is 13 to 15 , and the surface spall is 40 to 45 projectile diameters, which are in sharp contrast to the impact damage in a brittle aluminium target [1]. ErnstMach-Institut (EMI) had established a damage characteristics curve for viewport glass in the Russian Space Station MIR for spherical Al projectiles having masses roughly between about $3 \mathrm{mg}$ and $60 \mathrm{mg}$, impact velocities ranging between $4 \mathrm{~km} / \mathrm{s}$ and $9.1 \mathrm{~km} / \mathrm{s}$ [2]. The NASA Johnson Space Centre Hypervelocity Impact Technology Facility (HITF) had modified the damage equations for the Orbiter vehicle windows glass by conducting the twenty-five tests using $0.4 \mathrm{~mm}$ diameter $\mathrm{Al}$ projectile with impact velocities varying from $7 \mathrm{~km} / \mathrm{s}$ to $2.5 \mathrm{~km} / \mathrm{s}[3]$.

As a typical brittle material, fused silica glass has shown great difference from the ductile material. Generally there was a central pit in the front side of sample and a large area of spallation zone around central pit under hypervelocity impact. A lot of radial crack spread out of spallation zone. The rear side of sample had spallation zone, having been totally removed from sample, which was different from the front one, the spallation zone having been only partly detached and removed.

\footnotetext{
a e-mail: yangjiyun08@gmail.com
} 


\section{Impact testing}

\subsection{Test articles and test matrix}

In Beijing Institute of Spacecraft Environment Engineering (BISEE), hypervelocity impact characteristics in fused silica glass were studied by 37 impact experiments with different millimetre diameter projectiles up to the velocity of $7 \mathrm{~km} / \mathrm{s}$ launched by two stage light-gas-gun facility. There were two sizes of samples, $5 \mathrm{~cm}$ and $10 \mathrm{~cm}$ in diameter separately, but their thickness is the same as $1.2 \mathrm{~cm}$, used in experiments. The $\mathrm{Al}$ spheres projectiles were used with dimensions of $0.15 \mathrm{~cm}, 0.2 \mathrm{~cm}$, $0.25 \mathrm{~cm}$ and $0.3 \mathrm{~cm}$ in diameter, which impact velocities were varied from $2.80 \mathrm{~km} / \mathrm{s}$ to $7.44 \mathrm{~km} / \mathrm{s}$.

\subsection{Damage characteristics}

Table 1 has given all 37 test results. The results show that the sample would be perforated if the projectile is $0.25 \mathrm{~cm}$ in diameter, under impact velocity $3.95 \mathrm{~km} / \mathrm{s}$, as shown in Figure 1. Although the sample would not be perforated under impact velocity $3.72 \mathrm{~km} / \mathrm{s}$ (as shown in Figure 2), it had been in condition of critical perforation. So impact velocity $3.72 \mathrm{~km} / \mathrm{s}$ and projectile diameter $0.25 \mathrm{~cm}$ had been regarded as one point of ballistic curve for our silica glass. EMI had also obtained that impact velocity $4.0 \mathrm{~km} / \mathrm{s}$ and the same projectile diameter were at ballistic curve for $1.4 \mathrm{~cm}$-thick glass [2].

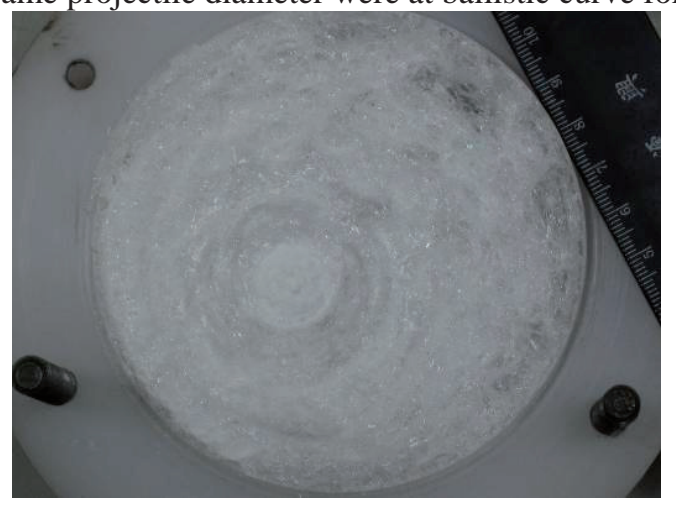

Fig. 1. Critical perforation of fused silica glass (Test \#31, projectile diameter $0.25 \mathrm{~cm}$, impact velocity $3.72 \mathrm{~km} / \mathrm{s}$ ).

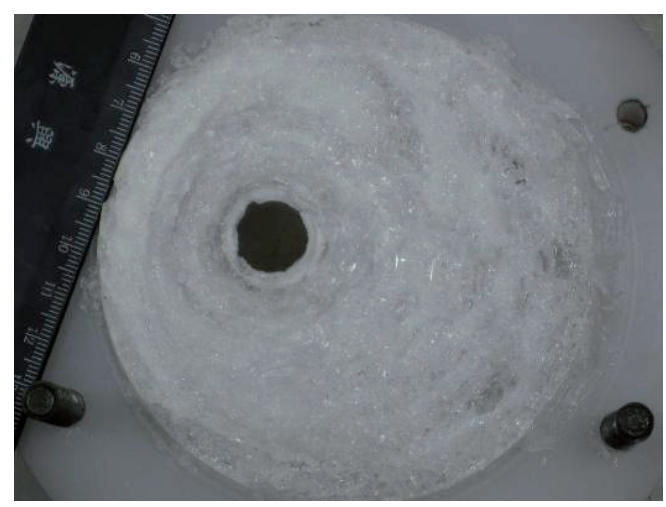

Fig. 2. Perforation of fused silica glass (Test \#32, projectile diameter $0.25 \mathrm{~cm}$, impact velocity $3.95 \mathrm{~km} / \mathrm{s}$ ).

\subsection{Results}


The impact characteristics of fused silica glass were analyzed by Olympus STM6 measuring microscope. The measured test data are listed in Table 1.

Table 1. Hypervelocity impact test result of fused silica glass.

\begin{tabular}{|c|c|c|c|c|c|c|c|c|}
\hline \multirow[t]{2}{*}{ NO. } & \multirow{2}{*}{$\begin{array}{l}\text { Projectile } \\
\text { Diameter } \\
(\mathrm{cm})\end{array}$} & \multirow{2}{*}{$\begin{array}{l}\text { Projectile } \\
\text { Mass (g) }\end{array}$} & \multirow{2}{*}{$\begin{array}{c}\text { Velocity } \\
(\mathrm{km} / \mathrm{s})\end{array}$} & \multirow{2}{*}{$\begin{array}{l}\text { Crater } \\
\text { Depth } \\
(\mathrm{cm})\end{array}$} & \multirow{2}{*}{$\begin{array}{c}\text { Spallation } \\
\text { Diameter } \\
(\mathrm{cm})\end{array}$} & \multicolumn{2}{|c|}{ Results } & \multirow{2}{*}{$\begin{array}{l}\text { Sample Size } \\
\text { in } \\
\text { Diameter }(\mathrm{cm})\end{array}$} \\
\hline & & & & & & $\begin{array}{c}\text { Front } \\
\text { Surface }\end{array}$ & Back Surface & \\
\hline 1 & 0.100 & 0.0014 & 2.99 & 0.235 & 2.850 & Crater & No Damage & 10 \\
\hline 2 & 0.100 & 0.0014 & 3.72 & I & I & Crater & No Damage & 10 \\
\hline 3 & 0.101 & 0.0015 & 3.94 & 0.190 & 2.368 & Crater & No Damage & 10 \\
\hline 4 & 0.102 & 0.0015 & 4.72 & 0.216 & 2.746 & Crater & No Damage & 10 \\
\hline 5 & 0.100 & 0.0015 & 5.06 & 0.181 & 1.156 & Crater & No Damage & 5 \\
\hline 6 & 0.100 & 0.0015 & 5.79 & 0.187 & 2.824 & Crater & No Damage & 5 \\
\hline 7 & 0.100 & 0.0015 & 5.93 & 0.190 & 3.004 & Crater & No Damage & 10 \\
\hline 8 & 0.100 & 0.0015 & 6.43 & 0.200 & 3.112 & Crater & No Damage & 5 \\
\hline 9 & 0.100 & 0.0015 & 6.50 & 0.217 & 3.082 & Crater & No Damage & 5 \\
\hline 10 & 0.100 & 0.0015 & 7.06 & 0.187 & 2.872 & Crater & No Damage & 5 \\
\hline 11 & 0.152 & 0.0051 & 3.28 & 0.387 & 1.456 & Crater & No Damage & 10 \\
\hline 12 & 0.150 & 0.0049 & 3.71 & 0.207 & 1.916 & Crater & Damage & 10 \\
\hline 13 & 0.151 & 0.0051 & 4.02 & 0.283 & 2.185 & Crater & No Damage & 10 \\
\hline 14 & 0.151 & 0.0049 & 4.85 & 0.306 & 3.774 & Crater & No Damage & 10 \\
\hline 15 & 0.150 & 0.0050 & 4.95 & 0.295 & 3.229 & Crater & Damage & 10 \\
\hline 16 & 0.152 & 0.0050 & 5.18 & 0.346 & 3.578 & Crater & No Damage & 10 \\
\hline 17 & 0.152 & 0.0051 & 6.02 & 0.222 & 4.620 & Crater & No Damage & 10 \\
\hline 18 & 0.151 & 0.0050 & 6.56 & 0.301 & 3.915 & Crater & Damage & 10 \\
\hline 19 & 0.151 & 0.0052 & 7.30 & 0.215 & 5.321 & Crater & Damage & 10 \\
\hline 20 & 0.201 & 0.0125 & 3.18 & 0.232 & 3.091 & Crater & No Damage & 10 \\
\hline 21 & 0.200 & 0.0125 & 3.26 & 0.354 & 5.630 & Crater & Damage & 10 \\
\hline 22 & 0.201 & 0.0124 & 4.02 & 0.380 & 5.216 & Crater & No Damage & 10 \\
\hline 23 & 0.200 & 0.0126 & 4.23 & 0.424 & 5.050 & Crater & Damage & 10 \\
\hline 24 & 0.201 & 0.0125 & 4.87 & 0.392 & 5.076 & Crater & Damage & 10 \\
\hline 25 & 0.200 & 0.0124 & 5.46 & 0.386 & 5.437 & Crater & Damage & 10 \\
\hline 26 & 0.201 & 0.0126 & 6.34 & 0.596 & 5.424 & Crater & Damage & 10 \\
\hline 27 & 0.201 & 0.0124 & 6.50 & 0.634 & 4.737 & Crater & Damage & 10 \\
\hline 28 & 0.200 & 0.0124 & 7.44 & 0.309 & 5.280 & Crater & Damage & 10 \\
\hline 29 & 0.251 & 0.0237 & 3.07 & 0.566 & 5.510 & Crater & Damage & 10 \\
\hline 30 & 0.250 & 0.0234 & 3.58 & I & I & Crater & Damage & 10 \\
\hline 31 & 0.250 & 0.0234 & 3.72 & 0.600 & 5.481 & Critica & Perforation & 10 \\
\hline 32 & 0.250 & 0.0233 & 3.95 & 1 & 1 & & foration & 10 \\
\hline 33 & 0.252 & 0.0235 & 4.74 & l & l & & foration & 10 \\
\hline
\end{tabular}




\begin{tabular}{|l|l|l|l|l|l|l|l|}
\hline 34 & 0.300 & 0.0391 & 2.80 & $/$ & $/$ & Perforation & 5 \\
\hline 35 & 0.300 & 0.0391 & 5.02 & $/$ & & Perforation & 5 \\
\hline 36 & 0.300 & 0.0391 & 5.23 & $/$ & $/$ & Perforation & 5 \\
\hline 37 & 0.300 & 0.0391 & 6.43 & $/$ & $/$ & & 5 \\
\hline
\end{tabular}

From Table 1, we can obtain the ballistic limit curve of fused silica, as shown in Figure 3.

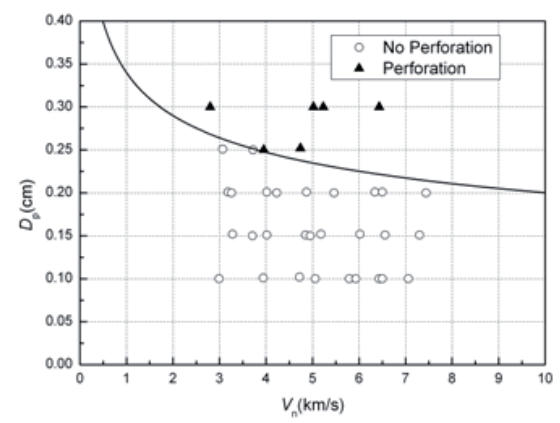

Fig. 3. The ballistic limit curve of fused silica

\section{Discussions}

\subsection{Damage equations}

The empirical damage equations were obtained from experiment data by the least square method. The relation between central pit depth and impact velocity was shown as equation (1) and the one between the front side spallation zone diameter and impact velocity was shown as equation (2).

$$
\begin{aligned}
& P_{\mathrm{f}}=0.96 d_{\mathrm{p}}^{1.26} V_{\mathrm{n}}^{0.67} \\
& D_{\mathrm{fs}}=9.83 d_{\mathrm{p}}^{1.03} V_{\mathrm{n}}^{0.57}
\end{aligned}
$$

Where $P_{\mathrm{f}}$ is the crater depth $(\mathrm{cm}), D_{\mathrm{fs}}$ is the front surface spall diameter $(\mathrm{cm}), d_{\mathrm{p}}$ is the projectile diameter $(\mathrm{cm}), V_{\mathrm{n}}$ is the normal component of the projectile velocity $(\mathrm{km} / \mathrm{s})$,

These empirical damage equations were compared with NASA damage equations [3],

$$
\begin{aligned}
& P_{\mathrm{f}, \mathrm{NASA}}=0.266 \rho_{\mathrm{p}}^{0.595} d_{\mathrm{p}}^{1.06} V^{0.995}(\cos \theta)^{0.496} \\
& D_{\mathrm{fs}, \mathrm{NASA}}=9.656 \rho_{\mathrm{p}}{ }^{0.373} d_{\mathrm{p}}^{1.183} V^{0.915}(\cos \theta)^{0.545}
\end{aligned}
$$

Where $\rho_{\mathrm{p}}$ is the projectile density $\left(\mathrm{g} / \mathrm{cm}^{3}\right), V$ is the projectile velocity $(\mathrm{km} / \mathrm{s})$, and $\theta$ is the projectile impact angle.

A comparison of the predicted impact crater depths using both equations to the measured test data is given in Figure 4. A similar comparison of the predicted front surface spall diameter using both equations to the measured test data is given in Figure 5. 


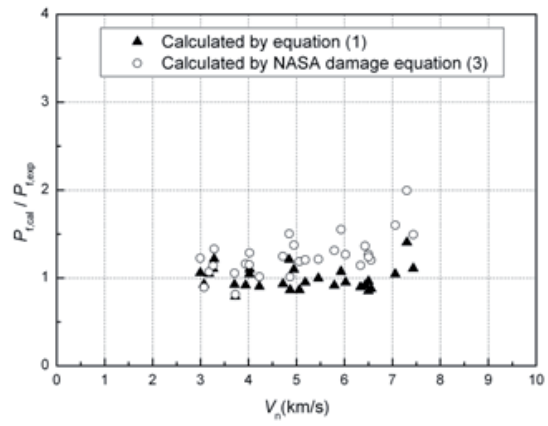

Fig. 4. The impact crater depths comparison between equation (1) and NASA damage equation (3).

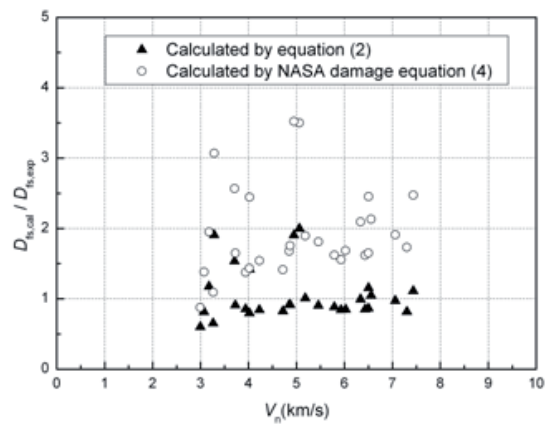

Fig. 5. The front surface spall diameters comparison between equation (2) and NASA damage equation (4).

From Figure 4 and Figure 5, two empirical equations obtained from our experiments had only a little difference from NASA equations considering the difference between samples. Because all impact angles of our experiments were $0^{\circ}$, it is necessary to supply several oblique impact data in the future test.

On the other hand, the comparison have been drawn between our damage equations and NASA damage equations using EMI test data [2], as shown in Figure 6 and Figure 7.

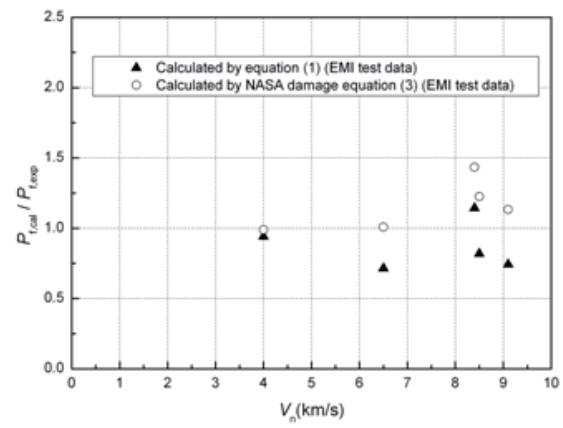

Fig. 6. Comparison between equation (1) and NASA damage equation (3) using EMI test data. 


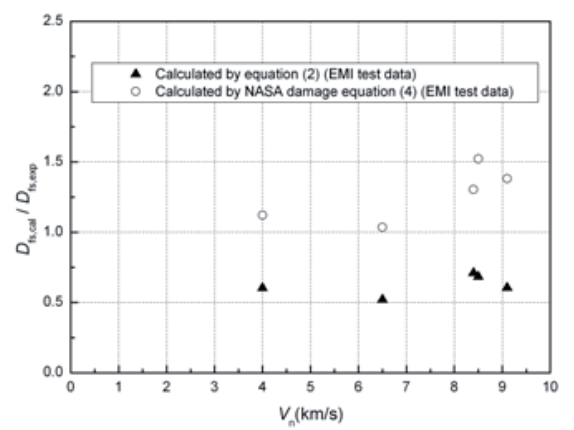

Fig. 7. Comparison between equation (2) and NASA damage equation (4) using EMI test data.

From Figure 6, equation (1) is generally suitable for EMI test data and NASA equation (3) is partly conservative.

\subsection{Edge effect}

Generally, small samples are desirable to conserve expensive target material. However, too small samples can result in larger edge effects that influence the extent of damage to them. Figure 8 shows impact test result for $5 \mathrm{~cm}$ diameter sample.

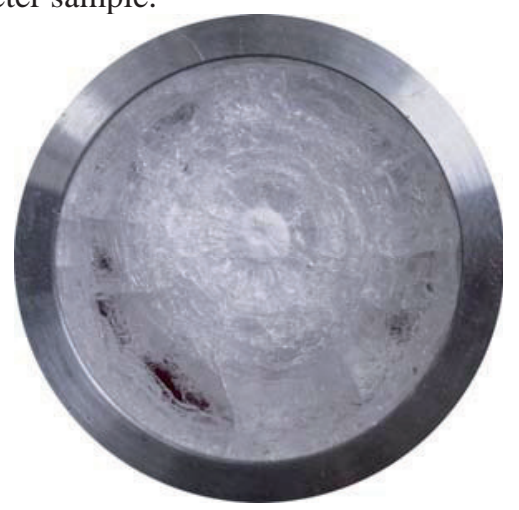

Fig. 8. Edge effect of impact test (Test \#8, $5 \mathrm{~cm}$ diameter target)

It is easy to be observed for edge effect damage when impacts are not centered on the target as illustrated in Figure 9. Generally, edge effect damage mainly appears on the back of target, which the damage location is symmetric with impact crater about the center of target. In Figure 9, the upper damage is done by edge effect and the lower one is the impact crater. 


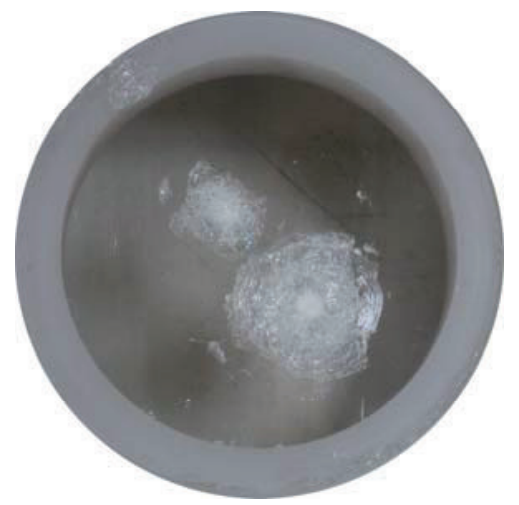

Fig. 9. Edge effect of impact test (Test \#1,10cm diameter target, not centered impact)

\section{Conclusions}

The impact damage equations have been obtained by 37 impact tests for fused silica glass and a comparison has been draw between our damage equations and NASA damage equations. From the comparison, our equations may be applied for design in engineering.

\section{References}

1. B. G. Cour-Palais, Int J Impact Engng, 5, 221 (1987)

2. E. Schneider, A. J. Stlip and G. Kagerbauer, Int J Impact Engng, 17, 731 (1995)

3. R. R. Burt, E. L. Christiansen, Int J Impact Engng, 29, 153 (2003)

4. R. E. Flaherty, AIAA69-0367 (1969)

5. D. Alwes, Int J Impact Engng, 10, 1 (1990) 